\title{
FORECASTING, VALUATION AND PORTFOLIO RETURNS OF STOCK MARKET EVOLUTION: PROBLEMS, PARADOXES AND EFFICIENT INFORMATION. WORLDWIDE IMPLICATIONS AND ROMANIAN EVIDENCE
}

\author{
Florin TURCAȘ ${ }^{1}$, Florin Cornel DUMITER ${ }^{2 *}$, \\ Petre BREZEANU1', Marius BOIȚA ${ }^{2}$ \\ ${ }^{1}$ Faculty of Finance and Banking, Bucharest Academy of Economic Studies, \\ Bucharest, Romania \\ ${ }^{2}$ Faculty of Economics, Engineering and Informatics, \\ "Vasile Goldiș" Western University of Arad, Arad, Romania
}

Received 05 February 2019; accepted 02 August 2019

\begin{abstract}
The purpose of this paper is to make a quantitative and qualitative critical analyse regarding the three important aspects of stock market evolution. First, the forecasting problems are presented and analyse in order to establish the main problems and the potential solutions. Second, the valuation problems are tackled in order to observe different trends and directions of solving these issues. Third, the portfolio return forecasts are mandatory in order to establish the results of the titles/market evolutions. The methods used in this research reveal the importance of adopting some important econometric tools in order to test the robustness of different main theories of the stock market and some important practices used among investors. The scope of the research was to give a quid pro quo in order to confer potential solutions regarding problems, paradoxes and efficient information of the stock market. The empirical results reveal that besides the critical side of the theories this paper sets a basis for a new eclectic approach regarding the probabilities that a title achieves certain values within a reasonable time frame. The main conclusion of this article suggests' that the current theories register some gaps regarding the adherence into stock markets' realities.
\end{abstract}

Keywords: stock markets, market forecast, business valuation, modern portfolio theory, technical analysis, betting.

JEL Classification: G11, G32, G41, F32.

\section{Introduction}

Stock market represents a whole assembly of financial relationships through it is realized the fund transfer between investors and users by using different instruments, mechanisms and

\footnotetext{
${ }^{\star}$ Corresponding author. E-mail: fdumiter@yahoo.com
} 
operators. These aspects converge to an autonomous system organized by its own markets in which they are traded assets and currencies. According to The Money Project, the market capitalization for all stock markets in the world is $\$ 73$ trillion, the global real estate value is \$ 217 trillion, and the value of the derivatives market is between \$ 544 trillion and \$ 1.2 quadrillion. The high values of these markets highlight their importance in order to understand and anticipate their evolutions is a natural and necessary approach. We don't aim at being Nostradamus, to foresee any event. This study is consistent with Taleb (2017) that it is difficult to foresee and predict the evolution of stock markets, precisely the potential financial crises still to come. It will be noticed that the market quickly absorbs some shocks (Trump election, idiotic declarations of Romanian officials) but cannot repair major mistakes (Black Monday, Dotcom or Subprime crises).

The 2011 tsunami in Japan is a good example of the fact that some catastrophes will continue to take us by surprise: the dams should have withstood, according to the calculations based on the experience of the whole recorded history. The only problem was that the waves were greater than any other observed so far. Engineers knew it was possible, but in the absence of a verifiable example, they reasonably estimated a level that proved to be easy to overcome. Analogy with the VaR (Value at Risk) is immediate: protection against "ordinary" variations has no effect when "unexpected" leaps occur. Stock market theory should be based on predicting the data of some securities, of the market in general, or at least on finding clues about the influence of events on the stock market. Therefore, market forecasts are the essence of any stock market study and they can only start from historical data. The ESMA and MIFID regulations explicitly state that any recommendation by advisors should include the statement that past performance is no guarantee of future returns.

And yet, the only starting point for predicting the future is past data. This statement holds true in social sciences ("who does not learn from the mistakes of the past is condemned to repeat them" - Winston Churchill), but also in the exact ones. From the widest scale (predicting the evolution of the universe depends on the understanding of its formation) to the smallest (quantum entanglement), history is determinant in knowing the future. The best example of the importance of business history is the appraisal of a company. Assessment standards require applying the market or the income approach, with only one exception: greenfield firms, newly established, for which only the cost approach can be applied (ANEVAR, 2018). No matter how elaborated the forecasts are, if there is no minimum experience, prudential assessment at cost is preferred.

The purpose of this article is to review the current capital market theory mainly focusing on the forecasts, valuation and portfolio evaluation. The approach of this study starts from a paradoxical situation highlighted in MPT manuals (Elton, Gruber, Brown, \& Goetzmann, 2014): "All investors will hold combinations of only two portfolios: the market portfolio and a riskless security." (two mutual fund theorem), market portfolio being referred as:" Each asset is held in the proportion that the market value of that asset represents of the total market value of all risky assets". Under these circumstances, instead of the investor, The Indices Committee decides which securities and their' weight are in the portfolio. From the experience of stock market sessions, most investment funds beat the market just because they ignore some securities from the index (DAX) and overweigh others. 
This article contributes to the systematization of the main theories, the discovery of their strengths and weaknesses, and the establishment of new research directions that, in the opinion of the authors, would be welcomed on the capital market. This article is not aiming at "reinventing the wheel", instead is suggesting looking for a Maglev. Section 1 presents the current state of the art by reviewing the literature, Section 2 presents the conceptual and empirical framework used in the study, Section 3 presents the research methodology approached, Section 4 summarizes empirical obtained results and their significance, Section 5 addresses the debates, discussions and recommendations in relation to the results obtained and the last Section summarizes the conclusions and shows the main directions in which we want to focus future research.

\section{Literature review}

The specialized literature in the field presents some particularly important aspects on the subject, which are worth mentioning and analysing. Markowitz (1952) represents a significant classical contribution in the portfolio selection theory regarding the optimal construction, developing and optimization of a selected value of returns. In the aftermath of this study, Sharpe (1964) gives several different solutions in the prediction of capital markets behaviour. Several decades later, Sortino and Price (1994) and Sortino and Satchel (2001) developed and improved different techniques in order to improve the investor financial performances, especially through post-modern portfolio theory and risk models. Chen (2010) has established the importance of the technical analysis in determining the future direction of the financial markets by presenting some interesting insights regarding the major types of the charts and presents also different arguments towards the technical analysis. Baker and Filbeck (2013) further improved the management and portfolio theory regarding pricing models, investment strategy, portfolio construction and Francis and Kim (2013) developed the economic literature regarding the modern portfolio theory by tackling some important aspects as: portfolio management, risk and uncertainty and portfolio construction and performance analyses.

Bako and Sechel (2013) perform a comprehensible analysis of the paradoxes of modern capital markets in the contemporary era. The findings of the study highlight the importance of identifying technical and fundamental anomalies that generate a significant impact on the price formation of financial instruments traded on the capital markets. Brynjolfsson, Rock, and Syverson (2017) use artificial intelligence systems to estimate and determine the evolution and price forecast of different titles. The conclusion reached by the authors is that Artificial Intelligence systems can lead to certain networks that can create a more efficient system of estimating the evolution of the price of different titles over different periods of time. Degutis and Novickyte (2014) developed a critical analysis of the literature that addresses the hypothesis of market intelligence. The authors point out that the dynamics of capital markets lead to the need for greater scientific research efficiency. The conclusion drawn from this study suggests that it is necessary to apply statistical methods to determine the randomized shift of stocks and the opportunities to obtain an additional profit through the usage of technical analysis strategies. Azevedo, R. M. P. Almeida, and D. P. Almeida 
(2012) use a data mining method as an additional and alternative way of forecasting by time series, the authors making a realistic critical review of the literature in the financial field as to the forecasts of short-term evolution of stocks. The authors conclude that although this approach has raised interest in the literature, there is still room for manoeuvre in combining the technical indicators with the fundamental indicators, combining these types of indicators leading to the possibility of integration of time series with different frequencies.

Zhang (2018) performs a study based on a set of 29 indicators of a neural propagation network from the perspective of technical analysis. The author analyses how neural network indicators are correlated with the technical analysis taking into consideration different parameters and different situations. The conclusion reached by the author is that the proposed model should be improved in future research in order to "achieve" a higher accuracy of predictions of the model. Fahling, Steurer, Schadler, and Voltz (2018) suggest that the weaknesses of the Black - Scholes - Merton model looks at the difference between model assertions in terms of volatility and how market reality is identified. The authors analyse the way in which volatility appears in reality and other parameters engraved in the model proposed by the authors, and they come to the conclusion that, in terms of volatility trading, the volatility of derivatives has to be presented and analysed under the auspices of their scope.

Aladesanmi, Metcalf, and Casalin (2018) analyse the macro - financial determinants of the US and UK stock markets for the time frame 1935-2015. The authors' conclusions suggest that the evolution of capital market integration has led to increased convergence, different crises, uncertainty in the convergence of economic policies and financial volatility. Demirer, Pierdzioch, and Zhang (2017) study the probability of stock returns on investment of a model type called quantile boosting. According to this study, the short - term yield of the shares may be somewhat predictable for very low levels of conditional distribution of returns. Litov, Moreton, and Zenger (2012) conclude that there is a paradox in choosing the optimal stock market strategy: on the one hand, the capital markets systematically discourage the uniqueness within the investment strategies of the economic entities; on the other hand, the uniqueness of a strategy is imperative to create profit, and this informational cost is associated with the value of the company. Sappideen (2009) analyses the efficiency of securities markets based on the information efficiency hypothesis. The author concludes that the securities markets are very competitive suggesting the need to establish a new theory to explain this inherent paradox.

The predictability of several exchange-traded funds were analysed by Gao, Han, Zhengzi $\mathrm{Li}$, and Zhou (2018) which came to the conclusion that predictability is robust both on some large volume day and on volatility days. Javadi, Ftiti, and Hdia (2017) undertake several empirical tests for the investigation of the informational efficiency hypothesis and reveal that it can be created good investment choices by commodities but it differs upon the different regions and classes. Longarela and Mayoral (2015) highlight the mispriced quotes suggesting that both the magnitudes and frequencies of these anomalies can gain impact upon investors' behaviour. In other studies, GARCH family models are used in forecasting several stock markets worldwide for explaining the volatility of the implied index (Pati, Barai, \& Rajib, 2018). Pyun (2019) analyse the predictability in aggregate stock returns within the variance risk premium method and finds out that this techniques is significant both statisti- 
cal and economical. The connections between weather and emerging stock market volatility was analysed by Shim, H. Kim, J. Kim, and Ryu (2015); the authors suggest that in cases of cloudy, windless and wet weather the volatility will increase, meanwhile in some lower weather conditions the investors will react asymmetrically.

The analysis between market cycles and stock markets through a type of scheme who combines cointegration analysis and different networks and suggested that market turbulence increases linkages (Singht, Roca, \& Li, 2018). Smales (2017) tackles the correlation between stock market returns and sentiment indices and reveals a strong relationship based on theoretical explanation of sentiment. Forecasting the stock market by Fourier analysis had no lead to robust and significant empirical results (Stadnik, Raudeliuniene, \& Davidaviciene, 2016). Symitsi, Symeonidis, Kourtis, and Markellos (2018) analyse different covariance of forecasting models and come to the conclusion that the results are robust when it is used high-frequency data models. Turcaș, Dumiter, Brezeanu, Fărcaș, and Coroiu (2017) analyse some important deficiencies of the Modern Portfolio Theory (MPT) in applying the statistics upon capital market. The authors conclude that there can be identified some statistical aspects that can lead to an improvement in applying the MPT in practice. Zhang, Zeng, $\mathrm{Ma}$, and Shi (2019) propose a way to improve stock returns predictability in a multivariate regression model in which are used different type of predictors; the authors conclude that the robustness of the results shows the feasibility of this strategy.

The portfolio selection has been analysed by several authors which evaluate and assess the importance of soundness portfolio by different investors and by taking into account several important features: Anghel, Dumitrescu, and Tudor (2015) which conclude that the classical model in portfolio returns is overfulfilled by the three factor model; Turcaș, Dumiter, Braica, Brezeanu, and Opreț (2016) highlight the usage and importance of technical analysis in portfolio selection and post-investment analysis, while Fulga (2017) uses behavioural content by taking into account the stochastic programming paradigm in the portfolio selection of an investor strategy.

Other authors reveal the importance us using GARCH estimation technique: Lupu (2015) in order to determine the several types of correlation upon European Stock Market; Marcu, Dobrotă, and Antoneac (Călin) (2017) for testing the day-of-the-week hypothesis patterns in conditional volatilities; Zivkov, Njegic, and Milenkovic (2018) in the establishment of several correlations and connections between four types on indices of the European Stock Market and German stock index; Arneric and Skrabic-Peric (2018) highlight the persistence volatility of the Central and Eastern emerging markets, while Joldes (2019) certificates the robustness of these types of models for evaluating the assessing the volatility of stock market indices. All these authors have come to similar conclusion that GARCH modelling techniques can be a quid pro quo for analysing the stock markets.

Saman (2015) makes a two dimension analyses both regarding the Romanian stock market and foreign exchange market by using the balance portfolio theory and the classical theory and came for the conclusion that both on the long run and on the short run there can be identified a significant correlation between BET and leu/euro currency exchange. It is important to reveal the volatility of Bucharest Stock Exchange from the investment perspective and risk management by using a whole set of high frequency variance estimators (Damian \& 
Cepoi, 2016). The efficient market hypothesis applied for the Central and Eastern European Stock Market for intraday price movements can be used as a path for the elimination of the market frictions (Anghel, 2017). Turcaș, Dumiter, Braica, Brezeanu, and Neagu (2018) apply the arbitrage principle vis - á - vis of Romanian Stock Market and come to the conclusion that this principle in not applying in cases in which investors' perceptions are to perform a higher yield than the interest rates of bonds. Applying different scenarios of stock market indices by using sentiment indices can explain to a certain level the connection of the volatility with different time series and several frequencies (Lupu, Hurduzeu, \& Nicolae, 2016).

Lungu, Bâra, Cărutașu, Pîrjan, and Oprea (2016) are analysing the renewable energy in Romania by using several neural networks and come to the conclusion that for the prediction and performance of several important indicators these techniques can be the optimal solution for producing green energy solutions in Romania. Georgescu (2016) evaluate and assess neural networks by using metaheuristics in optimization of the learning method and reveal that the neural networks are certain solutions in forecasting foreign exchange market and bankruptcy prediction. Ruxanda and Opincaru (2018) are modelling a large set of financial data for assessing risk management in the financial sector by using Bayesian neural networks; the authors came to the conclusion that by using neural networks it can be seen a robustness of trading experiment pairs with dependent Dirichlet.

\subsection{The need for forecasting}

The first step is to assess the need of market predictions. If strategies can be found to produce satisfactory results irrespective of the stock evolutions, adequate forecast is not necessary, with only retrospective attention paid to the movements of titles. Following most major stock indices with an upward historical trend, one might conclude that simply buying and keeping a share is enough. Eventually one can select different titles in its portfolio than they appear in indexes, but basically, we can rely on market growth without worries. This article suggests that buy and hold strategy is not the most appropriate. It is considered the

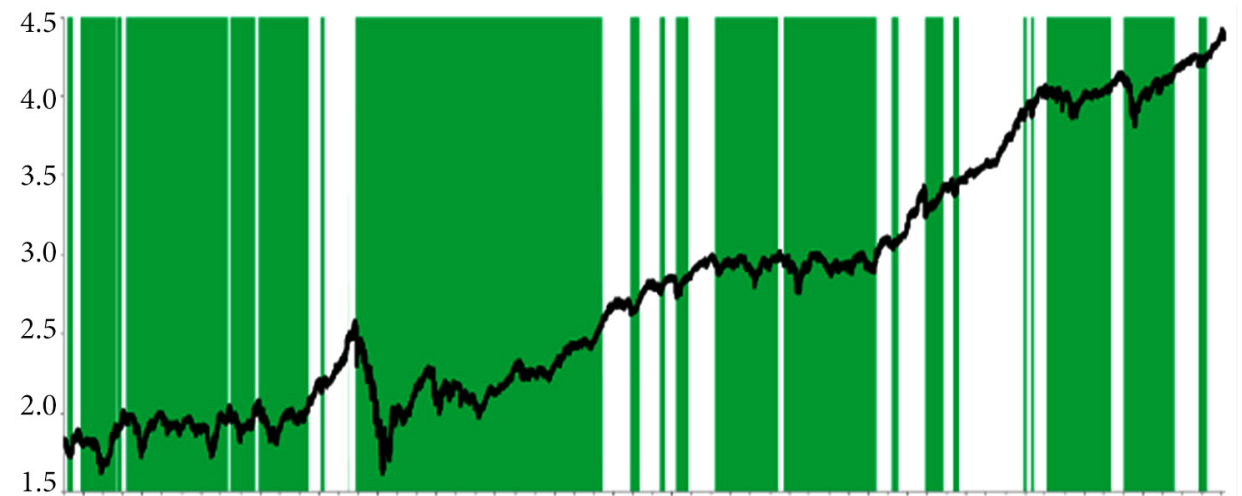

수울

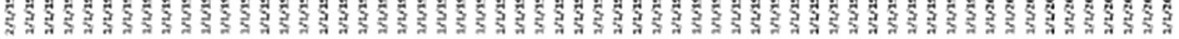

Figure 1. Wrong DJIA entry moment (beginning of green intervals) (source: own processing based on the data available on stooq, 2019) 
DJIA values (logarithmic chart - Figure 1), and it is marked on the charts the portions in which it did not recover after it suffered a decrease of more than $16 \%$. The drop percentage is randomly selected: not too low, because it is not a crisis, nor too much, because investors and especially rational speculators will not wait too long to mark their loss. Daily data of American DJIA on Nasdaq were taken from www.stooq.com, for the $1900 \div 5 / 21 / 2018$ period, and processed in Excel, which allows the random variation of the decrease percentage from which the crisis is considered.

Another study showed that neither the strategy of staying on the winning side of the market yields optimal returns under any circumstances. As a principle, the position should be long in the bull and short in the bear market periods. The problem is evident in flat-periods i.e. trading-ranges. The $\mathrm{X}$ and 0 strategy (Turcaș, 2008) is based on point \& figure charts with reverse box $=1$ and consist of changing the position as the symbol (column) changes in the chart. Gain/loss is determined by counting the symbols in the same column minus 2 (losses due to the reversal of the investment position because of the trend change), which is then multiplied by the range of variation. This strategy also didn't work on flat market conditions. In another study, it is shown that financial results are statistically modest if they are applied only the buy-and-hold strategy, or by applying the tactics of changing the investment position to a certain threshold, or by acting on the intersections of mobile environments (as the first automated software trading).

In conclusion, stock investments do not produce enough returns without realistic stock market forecasts. It results that the development of accurate and realistic forecasting of market developments and stock quotes is crucial for consistent stock market results. Therefore it will be analysed the main methods of anticipating stock market developments. Financial markets are a mix of objective and subjective factors, predictable and random events, influenced by known economic factors but also by uncontrollable forces. Thus, the titles have as object or support actives well-defined economic elements (commodities, companies, currencies, etc.) but are managed by people, with different feelings, knowledge, intentions, and attitudes. Companies' budgets, mineral extraction, projects to be funded are based on solid theoretical grounds; the world we live in is a dynamic one in which strange attractors appear regularly, leading to unpredictable chaotic situations. At the macro- (mondo-) economic level, the main trends are known; nevertheless, no one correctly predicted the fall of communism, the failure of the Arab revolution in Syria, or the pacification of the Korean peninsula.

The objective part: the physical or economic support, the statistical side and the technical elements are of course already studied scientifically. Part of the subjective side is also analysed: behavioural studies (Cartwright, 2018), including those related to the herd-spirit, are known on the stock market. Alarming is, however, that a simple search on Google with the theme "astrology + stock" returns about 14 million results. In this way, the subjective reaction, applied to a lot of market participants, can ultimately lead to a stock movement in the sense of confirming predictions. Which confirmation, by domino effect, can lead to increased trust of a part of the public in mystical approach. As to the precision of the forecasts, a proof in this regard is a 2005 work (Richard, 2005) in which the forecast for the next 10-year was attempted by astrological methods. Visions had only one weak point: they failed to foretell the stock market crisis of $2007 \div 2009$. Even prestigious publishers print books (Pesavento 
\& Smoleny, 2015) dedicated to the application of astrology in finance, hence encouraging superstitious approaches.

\subsection{Valuation and its problems}

The valuation date is essential in appraisals. The reference to it is thus set by the standards (International Valuation Standards Council, 2017): "On the valuation date" requires that the value is time-specific as of a given date." The valuation carried out by the DCF (Discounted Cash Flow) approach requires the forecasting of future financial flows, i.e. it is based on financial figures from next periods, but the cost of capital is the one calculated/taken up to date. No studied material mentions even the need to predict capitalization rate evolution, although it is obviously variable (Figure 2). From the valuation point of view, it is a big difference if the cash - flow is multiplied $(1 / \mathrm{r})$ by 17.2 or by 10.6 . Cost of capital was taken from Damodaran's website, the data being processed in Excel.

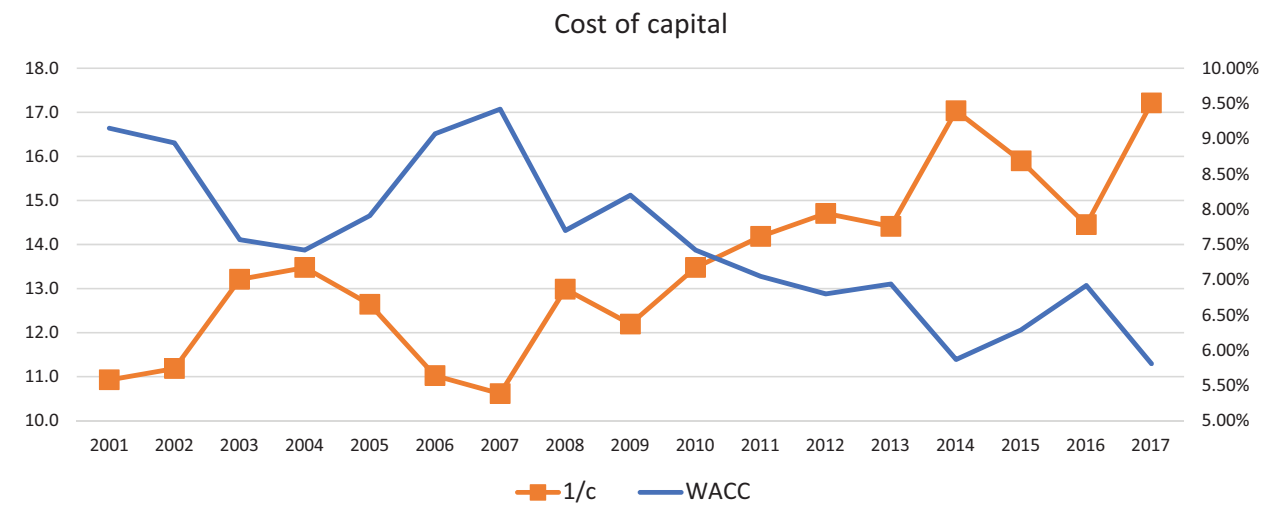

Figure 2. Cost of capital variation (source: own processing)

Thus, a paradox appears: the value at the date of valuation (today) is based on forecasting future results but does not foresee also the evolution of investors' expectations regarding the return on investment and the risk. The solution adopted is obviously a protection for the valuator, mentioned in the standards itself ("Because markets and market conditions may change, the estimated value may be incorrect or inappropriate at another time."). But the approach virtually cancels any confidence in the company's value (trading price) forecasts.

"Typically, the higher the value of the expected return, the higher the value of risk associated with the asset..." (Mago, Wang, \& Modave, 2010) is the statement that summarizes the preconceptions that underlie the modern theories of the portfolio. The assertion is contradicted by both practice and assessment theory.

The theory of valuation uses Gordon's (Dividend Discount Model) formula as a fundamental relation:

$$
V=\frac{D_{1}}{r-g},
$$

or more in detail, the calculation formula of DCF (Schmidlin, 2014): 


$$
V=\sum_{t=1}^{\infty} \frac{F C F_{t}}{(1+r)^{t}},
$$

where $V$ is the value of the company, $D_{1}$ is the expected dividend next year, FCF is the free cash flow for the entity, $r$ is the cost of capital, and $g$ is the expected long-term growth rate into perpetuity. Indeed, free cash flow is the measure of return, being distributable to financiers (shareholders and borrowers), and $r$ is a sum of risk-free interest rate plus a risk premium.

The cost of capital is taken from market data: "the cost of capital is the expected rate of return that the market participants require in order to attract funds to a particular investment" (Schmidlin, 2014), which are usually presented on industries. It turns out that the whole industry has a single value of systematic risk (which is logical), an assertion which contradicts the Modern Portfolio Theory approach. MPT determines the risk of each individual title, in the form of the dispersion of its return. Cost of capital is the measure of risk that investors assume. Since all appraisers take into consideration the mean value of an industry, this contravenes MPT, which calculates the individual risk, distinct for each security. Moreover, when market data is insufficient, the valuation rules allow the construction of cost of capital in stages, by summing up systemic and non-systemic risks, ie on totally different bases than those used in MPT.

Moreover, some authors (Philippe, 2010) believe that the WACC:

$$
r=W A C C=\frac{D}{D+E} r_{D}+\frac{E}{D+E} r_{E},
$$

should be calculated based on the industry equity $(E)$ credits (debts, $D$ ) ratio, rather than the valued company, because of the Modigliani-Miller leverage theorem. Here, $r_{E}$ and $r_{D}$ are respectively the cost of equity and the cost of debts.

In practice, this study checked the average and the dispersion of titles on the Romanian capital market. Modern Portfolio Theory MPT (mean-variance theory) uses the average of returns as a measure of return and the variance (dispersion, mean square rate of return) as a measure of risk (although it measures at most uncertainty). We considered the Romanian Stock Exchange BET index components for the period 11/02/2017 $\div 04 / 30 / 2018$, data down-

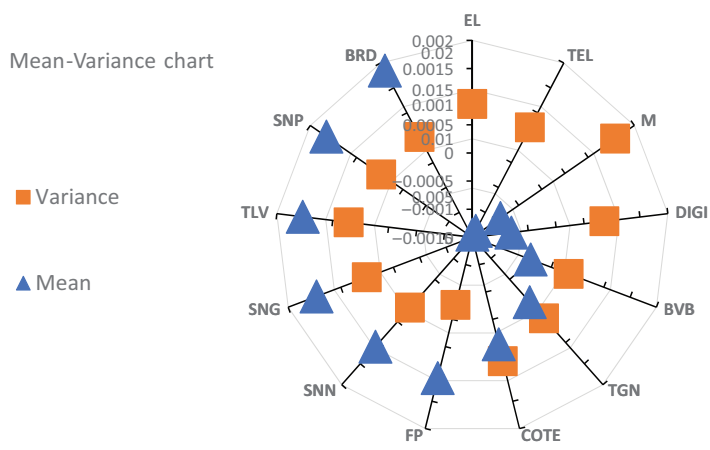

Figure 3. Mean - Variance chart for BET companies (source of data: Bucharest Stock Exchange (BSE); source: own processing based on the data available on Betfair, 2019) 
loaded from the BSE website. If the first sentence in this paragraph would be true (if there should be a direct relationship between return and risk), the chart in Figure 3 should reveal a direct link between mean and variance (the two charts should have been concentric), which obviously does not happen. The graph shows that there are companies with good return and low risk as well as companies with modes return and high risk. For each security, the average and spread of daily return on the $11 / 2 / 17 \div 4 / 30 / 18$ period was calculated.

\subsection{Modern portfolio theory}

The MPT proposes efficient portfolios by maximizing returns for a given risk, i.e. minimizing risk for a pre-established return (Pratt \& Grabowski, 2010). As mathematical quantities, daily earnings average per share $\mu$ are used as the return amount, the mean square deviation $\sigma$ (dispersion) as a measure of risk, and the correlation $\rho$ of titles is used to avoid systematic risks. The locus in the $\mu \sigma$ plane of the points that meet the optimum Paretto portfolio conditions is a hyperbole equation (Alțăr, 2002) of:

$$
\sigma_{P}^{2}=\frac{1}{D} \times\left[A R_{P}^{2}-2 B R_{P}+C\right]
$$

where: $A=1^{T} \Omega^{-1} 1, B=1^{T} \Omega^{-1} \mu, C=\mu^{T} \Omega^{-1} \mu \quad D=A C-B^{2}$, with $\mu$ returns, $\mathbf{x}$ weights vectors, and $\Omega=\left(\sigma_{i k}\right)$ covariance matrix.

\subsubsection{Theoretical deficiencies}

The theory presents many flaws, including:

- First, return measurement is questionable:
- If the returns are defined as percentages: $R_{i}=\frac{\left(c_{i}-c_{i-1}\right)}{\left(c_{i-1}\right)}$, where $\mathrm{r}_{\mathrm{i}}$ is the return and $c_{i}$ the $i$-th day price, then the average return is not equal with average of returns. A decrease of $50 \%$ requires a $100 \%$ increase next day to reach a 0 variation of the price. For example, for the closing prices of SIF1 transactions on the BSE REGS market, between 01/04/2010 $\div 05 / 09 / 2017$ (1,838 trading days), the difference between the total return (final vs. initial) and the average mean of daily

returns is $30.545 \%$;
- If the return is defined logarithmically: $R_{i}=\log \left(\frac{c_{i}}{c_{i-1}}\right)=\log \left(c_{i}\right)-\log \left(c_{i-1}\right)$, then the portfolio return is not a linear combination of composing returns;

- If the return is defined in absolute terms: $R_{i}=c_{i}-c_{i-1}$, then its weight will depend on the measurement units of stocks value ( $\$$ or $\$$ );

- Second, the risk measure by variance is also questionable, being more a mathematical formality (the media and dispersion unambiguously defining the Gaussian distribution) than a practical amount. Thus, the theory requires a risk-free title, which is usually assimilated to long-term bonds. But the yields of bonds vary over time, so they have a nonzero dispersion. Thus, the use of dispersion as a measure of risk itself is contradicted: although they have a non-zero variance, the risk is zero (American state bonds have never encountered payment problems in history, so they are practically risk-free). 


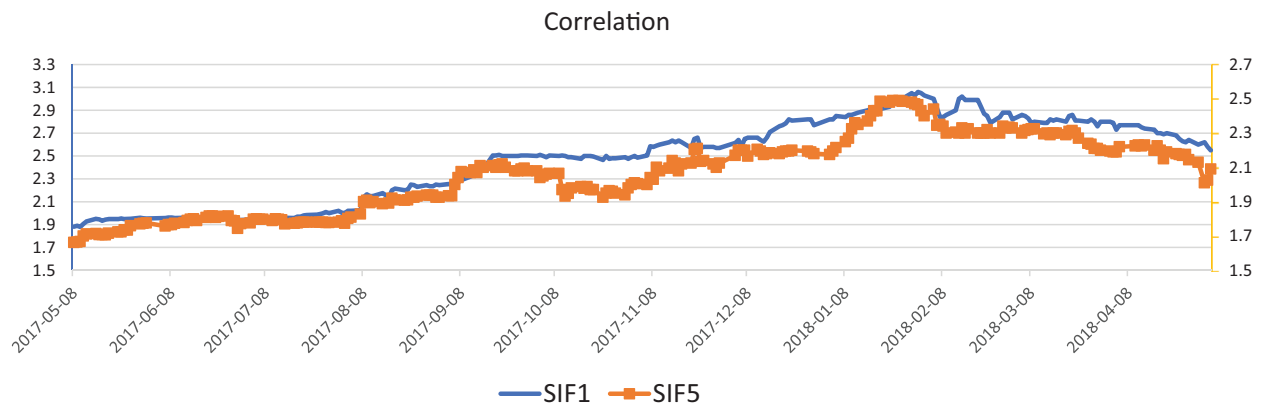

Figure 4. Practical correlation between 2 Romanian titles (source: own processing based on the data available on Bucharest Stock Exchange, 2019)

- Third, the correlation is verified only linearly (through statistical covariance), thus omitting co-movements between titles with certain practical implications.

An eloquent example on the Romanian market is the similar evolution of SIF1 and SIF5 (the same type of companies: closed-end investment funds of special type), clearly highlighted in Figure 4 and well known by market specialists:

The mathematical correlation between them is 0.2960929 in the studied period: $05 / 08 / 2017 \div 05 / 04 / 2018$. The explanation is simple: the mathematical formula of the correlation:

$$
\sigma_{x y}=\operatorname{COREL}(X, Y)=\frac{\sum(x-x)(y-y)}{\sqrt{\sum(x-x)^{2}} \sum(y-y)^{2}}
$$

only verifies the linear linkage between titles, which is indeed not very high in the analysed case. This result (a weak correlation) can be challenged, by correlation technique for nonlinear data or using wavelet analysis. By this we give up the MPT, whose mathematical expression requirement is a linear correlation of the type from formula (5). This study specifically chose the same type of companies because they are both intuitive and economical alike, so it is natural there is a high correlation between them. However, the linear mathematical correlation (imposed by MPT) is reduced, due to daily random fluctuations that do not affect the overall picture but disrupt exactly the mathematical results.

Last, although the purpose of the theory is precisely to distribute the risk, the most important of these was omitted (due to the singularity of the covariance matrix): titles that vary perfectly correlated and which should be selected to avoid non-systemic risks. Note that the matrix of covariates $\Omega$ must be inversible, i.e. it is not permissible for the titles to be perfectly correlated, positive, or negative $\rho_{j k} \neq \pm 1$. Although theoretic the covariance matrix singularity problem can be solved (for example, using Moore-Penrose inverse), MPT's philosophy is not appropriate for speculators. Let's assume that an investor knows well and predicts an asset correctly. This investor will specifically look for titles that vary similarly in the portfolio to spread non-systemic risks. Moreover, if there is a lag (a delayed reaction) between the variations of securities, the investor will be able to act accordingly on the subsequent title (by arbitrage or speculation) with great chances of success. 


\subsubsection{Practical deficiencies}

However, the theory would be attractive if it were practically applicable. For this, the analyst should be able to predict the daily values of all portfolio titles. This is the only way he could feed the theoretical model with data: he could calculate returns, risks and covariances. "In order to calculate covariance and correlation, percentage return data for consecutive subintervals (for example, days or months) are needed without any data missing for any of the two relative return time series" (Schulmerich, Leporcher, \& Eu, 2015). Correlation can be estimated from historical data, but errors can be substantial. For example, replacing a single quotation at random, the correlation changes radically. Let's assume that on 04/19/2018, SIF5 had a spike and instead of 2.15, the quote would have been 3.00, with all the remaining SIF1 and SIF5 quotes unchanged. In this case, the correlation would have been 0.0780267 instead of 0.2960929 as it was. A substantial difference can be noted, difference which was determined by a single digit change (or perhaps even a bias, the error being possible for large amounts of data).

One would expect that the theory would indicate methods to achieve these forecasts throughout the given period (one year, for example). It was not founded in any bibliographic material studied on this subject any reference to any appropriate forecasting technique. Or, in the absence of accurate predictions, the theory is not applicable. Here comes a paradox. Suppose we have accurate forecasts for all stock exchange prices, for all the titles, over the entire forecasting period. In this case, the application of the MPT would be inadvisable: the most profitable titles at the respective intervals will be chosen, regardless of their variation. Thus, the paradox is that if theory were applicable in practice (if there is available all the necessary data), then applying theory to practice would be useless. If the data are not reliable, then the optimal portfolio has no guarantee of accuracy. Basically, if all future returns are known, as theory requires, there is no risk, even if there are fluctuations (even if the variance is not zero).

\section{Conceptual framework}

Based mainly on the study of charts realized by Murphy (1999), Lim (2016) and Greenblat (2013), the technical analysis attempts to predict the evolution of titles by determining the trends, the repeatability of the patterns, the calculation of the indicators and the oscillators. The technical analysis is constantly used by practitioners, but its precision is questionable. Of course, charting alone cannot provide constant remarkable results, as anybody can experience on chartgame.com. A comparison of these approaches is presented in Figure 11. Trading data and financial statements were taken from the BSE website, the data being processed in Excel. The graph reveals that there are times when the market is strong, so TA prevails, but also moments of lull, in which FA is decisive. Important for investors, respectively for determining trends and relevant levels, the local extremes must be first detected. To automate the technical analysis, the basic approach starts from using algorithms to localized regional maxima and minima, based on Rolling Window or Perceptually Important Points methods (Tsinaslanidis \& Zapranis, 2016). The Rolling Window method sets local maxima and minima by traversing the entire curve and recording extreme values over a limited width portion. 
The method has the advantage of simplicity, but also has practical deficiencies:

- Find extremes that are not of real interest to investors (local extremes even in flat markets);

- Find successive extreme of the same type (for example, a maximum after another maximum, without a minimum between them);

- It does not highlight some important movements, although they appear visually obvious and of interest to investors;

- A too small window highlights too many local extremes, especially in periods of trading; a too big one misses interesting local extremes, especially in times of trading (volatility) of the market.

Perceptual Important Points (PIPs) define the regional maxima and minima through maximal Euclidian Distance ED, Perpendicular Distance PD or Vertical Distance VD relative to the Initial-Final IF line. These points have advantages as well as many disadvantages (Figure 5).

In Figure 6 it is noted that points A, B and C, although they are obviously very important maxima for the technical analysis, will not be detected as PIPs because they are very close to the IF line, thus having the PD distances mentioned much smaller than other non-interest points (in fact, points $\mathrm{A}, \mathrm{B}$ and $\mathrm{C}$ have the minimum distances from IF in the chart). From Figure 7 follows that point $\mathrm{C}$ is $\mathrm{PD}$ type PIPs $\left(\overline{C C_{1}^{\prime}}>\overline{B B_{1}^{\prime}}\right)$ only if is analysed the growth

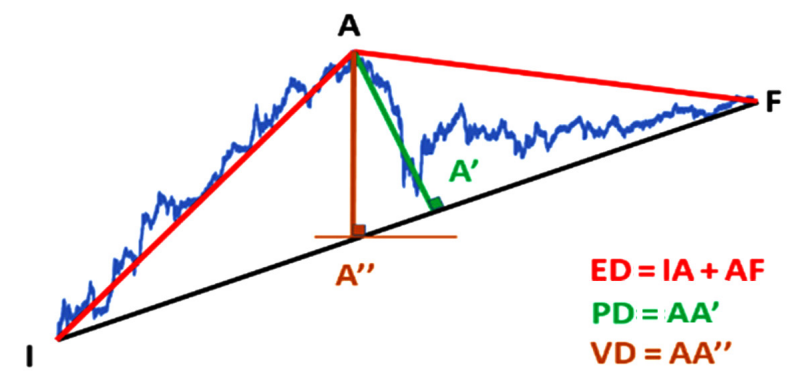

Figure 5. Defining Perceptual Important Points (PIPs) (source: own processing)

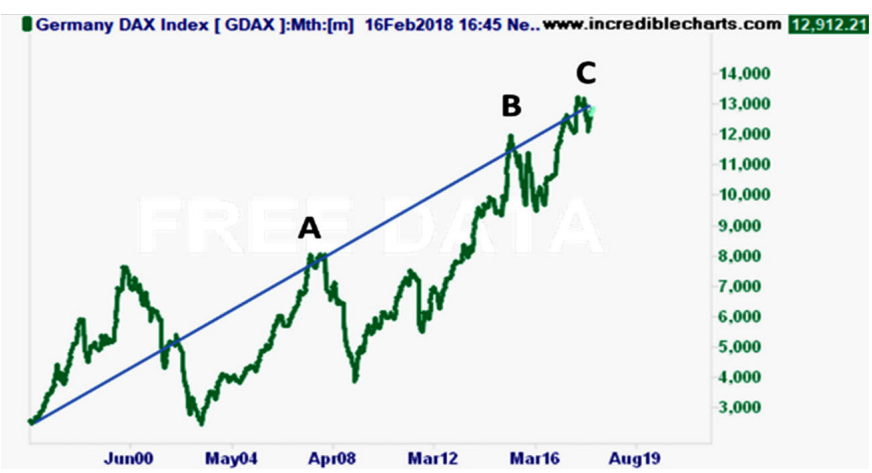

Figure 6. Flaws in detecting PIPs on DAX (source: own processing) 
portion IA (as suggested in the literature), but if we consider the whole chart (IF), point B is the PD PIPs $\left(\overline{C C_{2}^{\prime}}>\overline{B B_{1}^{\prime}}\right)$. Obviously, selecting PIPs should not depend on the analysed portion of the chart.

The situation is even more significantly revealed if it is analyzed PIPs from the VD prism. In Figure 8 it is highlighted that point $\mathrm{C}$ is PIP if we consider the IA part of the chart, and $\mathrm{B}$ if we consider the whole chart. In this case, also from the trend the point of view, point $\mathrm{C}$ is less important than $\mathrm{B}$, because $\mathrm{B}$ can be a relative maximum, which cannot be omitted from the analysis. Another major deficiency is that these PIPs depend on the scale used for the horizontal and the vertical axis. Since the distance between two points $A\left(x_{1}, y_{1}\right)$ and $B\left(x_{2}, y_{2}\right)$ is $d_{A B}=\sqrt{\left(x_{1}-x_{2}\right)^{2}+\left(y_{1}-y_{2}\right)^{2}}$ it is clear that changing the dimensional ratio between $\mathrm{x}$ and $y$ (different scaling of axes) can alter the ratio of the points distances. Thus, the most important problem in computerization of technical analysis is not solved: the establishment of relative maxima and minima, which determines trends and inflection points.

\section{Methodology}

The most important element of technical analysis is the awareness that the market is moving in trends. The statistical analysis, often used by theoreticians, cannot take trends into account: the order of the data does not have any influence on the statistical result. Or, price movements in trends cannot be neglected, despite the theories of informational efficiency or random walk. One of the most commonly used indicators is MACD, which well predicts trend changes.

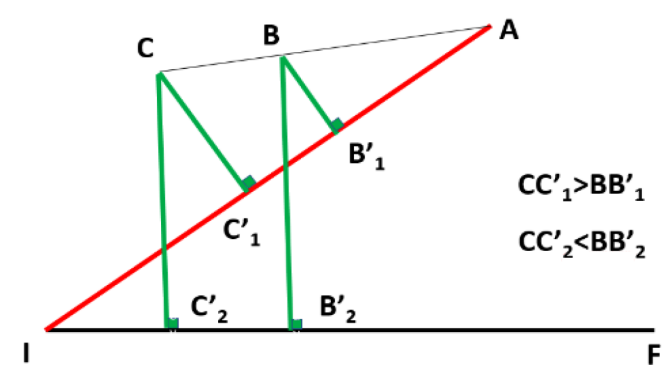

Figure 7. Relative and absolute PIPs (source: own processing)

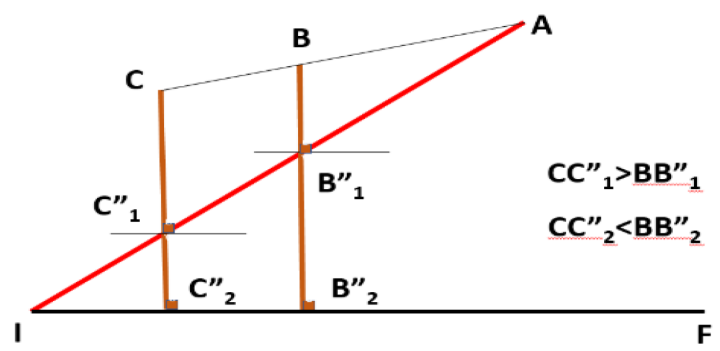

Figure 8. Relative and absolute PIPs through VD prism (source: own processing) 
In Figure 9 can be noticed that all the bull signals (automatically plotted by the graphics program) are false, except for the starting point of the boom (April 2003) and of the beginning of the crisis (November 2007). Automated trading systems offer good results, especially during strong trend periods. A classic model is based on the intersection of the moving averages: where the shorter moving average (or prices, mathematical equivalent to the one-day average) exceeds the longer average (multiple days), the position taken is long; it changes to short as soon as the intersection of averages took the longer aver the shorter average.

Longer averages miss in-out moments (diminishing gains), and short ones give too frequent signals. Thus, although it may be an example of a stock market strategy that does not require forecasting (responds to changes in market conditions alone), the automatic systems based on the averages intersections does not always give good results. It is know that surprising economic phenomena will always emerge, and they will influence (or not!) the stock market. They will be absorbed, but the differences will be brought about of the amount of time and costs. Classical examples are the leap of the Swiss franc following the abolition of the Swiss Bank's cap, the Brexit, or the election of US President Donald Trump (Figure 10). In the hypothesis of informational efficiency of the market, the Grossman - Stiglitz (De Prado, 2018) paradox argues that no one would look at companies anymore, since prices are freely available and faithfully reflect the firm's situation. But without any analysis, how can we know if prices are "fair" (i.e., if they reflect the intrinsic value of the title)?

The situation in which the market would be informational efficient, it would not lead to GARCH (Franco and Zakoian, 2010) or ARMA models, but would show a direct correlation between the Technical Analysis TA and the Fundamental Analysis FA. The quotations, except for a delay between the occurrence of the information and its transposition in prices,

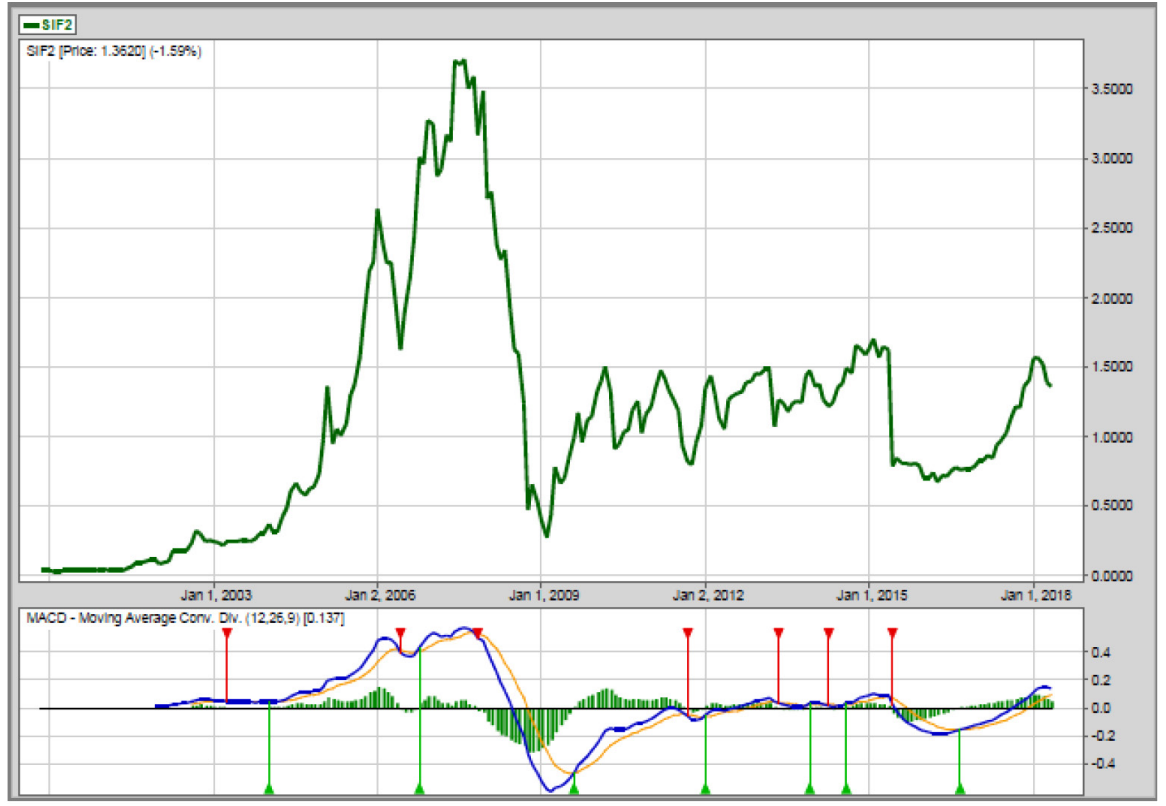

Figure 9. MACD applied to SIF2

(source: own processing based on the data available on ifbf Finwest, 2019) 
should remain constant between financial reports: there would be no reason to vary. A direct correlation between TA (evolution chart of securities) and FA (the economic reality of the issuer) would mean that price formation in the market depends only on the status and results of the issuer. Price positioning in relation to company fundamentals (practical, stock market indicators) would solely depend on general market conditions. Thus, all available information would be embedded in the spot price, thus checking the information efficiency of the market.

Important quotation movements would only be justified around the time of publication of financial results or major economic fluctuations. The fact that daily prices are not recursively correlated (there is no iterative mathematical link between them) proves nothing but that binary options are a simple gamble.

According to Figure 11, in real life, applied to BRD (a Romanian bank that is part of the BET index of the BSE), information efficiency can be interpreted in TA-FA terms. In "sentimental" periods of strong growth (up to 2007) and then by strong stock market declines (up to 2009), the prices did not reflect the company's financial data at all, investors acting solely based on the stock market trends. During the "cooling down" period (after the financial crisis), the financial results and the prices are clearly correlated, with no other stock market movements than those related to the adjustment of the quote to the realistic value of the company. This portion of the graph reflects information efficiency, more accurately than autoregressive statistical correlations.
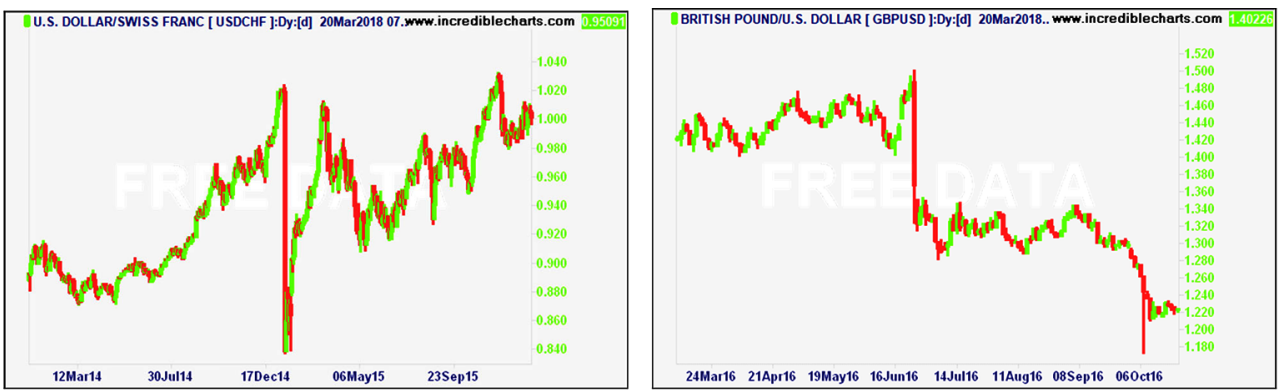

Figure 10. The stock market effect of unexpected events (source: own processing created in the program IncredibleCharts)

Technical vs Fundamental Analysis

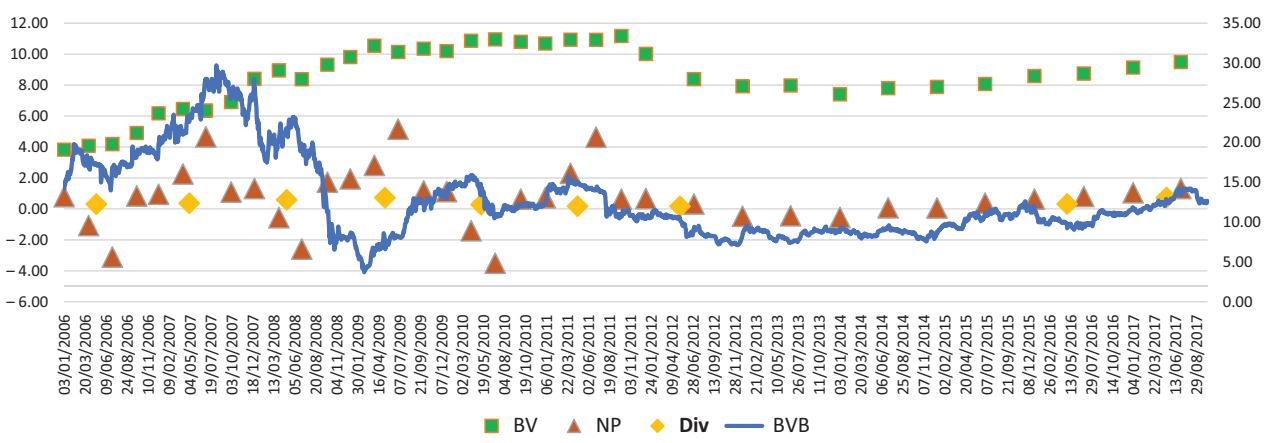

Figure 11. TA-FA correlation as a reference for information efficiency (source: own processing) 
In order to verify ARMA/GARCH theories it was taken into consideration closing quotations of SIF1 on BSE, from 2000 to date $(5 / 13 / 19$, for which it were calculated daily percentage return. The results of the Matlab garchfit function reveals that there is no link between daily yields (ARMA $(0,0,0)$, the variance being random, Gauss-ian, $\operatorname{GARCH}(1,1)$ type (Figure 12):

The result is graphically confirmed, Innovations being similar to Returns (Figure 13).

\begin{tabular}{|c|c|c|c|c|c|}
\hline Field $\triangle$ & Value & & Min & Max & \\
\hline 田 exitflag & 5 & & 5 & 5 & \\
\hline 30 warning & 'No Warnings' & & & & \\
\hline ab converge & 'Function Converged to a Solution' & & & & \\
\hline 76 constraints & 'Boundary Constraints Active: Standard Errors May Be & Inaccurate' & & & \\
\hline covMatrix & $\langle 4 \times 4$ double $>$ & & $-3.3801 e-05$ & $4.7918 \mathrm{e}-05$ & \\
\hline iterations & 21 & & 21 & 21 & \\
\hline 思 functionC... & 141 & & 141 & 141 & \\
\hline 䁬 lambda & $\langle 1 \times 1$ struct $\rangle$ & & & & \\
\hline \begin{tabular}{|l} 
MATLAB Varia \\
May 14,2019 \\
\end{tabular} & ble Editor: Coeff & & & & $\begin{array}{l}\text { Page } 1 \\
\text { 12:29:38 PM }\end{array}$ \\
\hline Field $\_$ & Value & Min & Max & & \\
\hline Comment & $<1 \times 41$ char $>$ Mean: $\operatorname{ARMAX}(0,0,0)$; Variance: $\operatorname{GARCH}(1,1)$ & & & & \\
\hline Distribution & 'Gaussian' & & & & \\
\hline 画c & 0.0011 & 0.0011 & 0.0011 & & \\
\hline Variance... & 'GARCH' & & & & \\
\hline 田p & 1 & 1 & 1 & & \\
\hline 思Q & 1 & 1 & 1 & & \\
\hline 田 $\mathrm{k}$ & $1.0140 \mathrm{e}-05$ & $1.0140 \mathrm{e}-05$ & $1.0140 \mathrm{e}-05$ & & \\
\hline 思GARCH & 0.8204 & 0.8204 & 0.8204 & & \\
\hline 田 ARCH & 0.1796 & 0.1796 & 0.1796 & & \\
\hline
\end{tabular}

Figure 12. Results of applying the garchfit function in Matlab (data source: BVB. SIF1 closing quotations between 1/1/2000 $\div 5 / 13 / 2019$ ) of: $\epsilon_{t}=0.8204 \sigma_{t-1}^{2}+0.1796 \epsilon_{t-1}^{2}$ with Gaussian innovation distribution and $\sigma_{t}^{2}=1.014 \cdot 10^{-5}+0.8204 \sigma_{t-1}^{2}+0.1796 \epsilon_{t-1}^{2}$
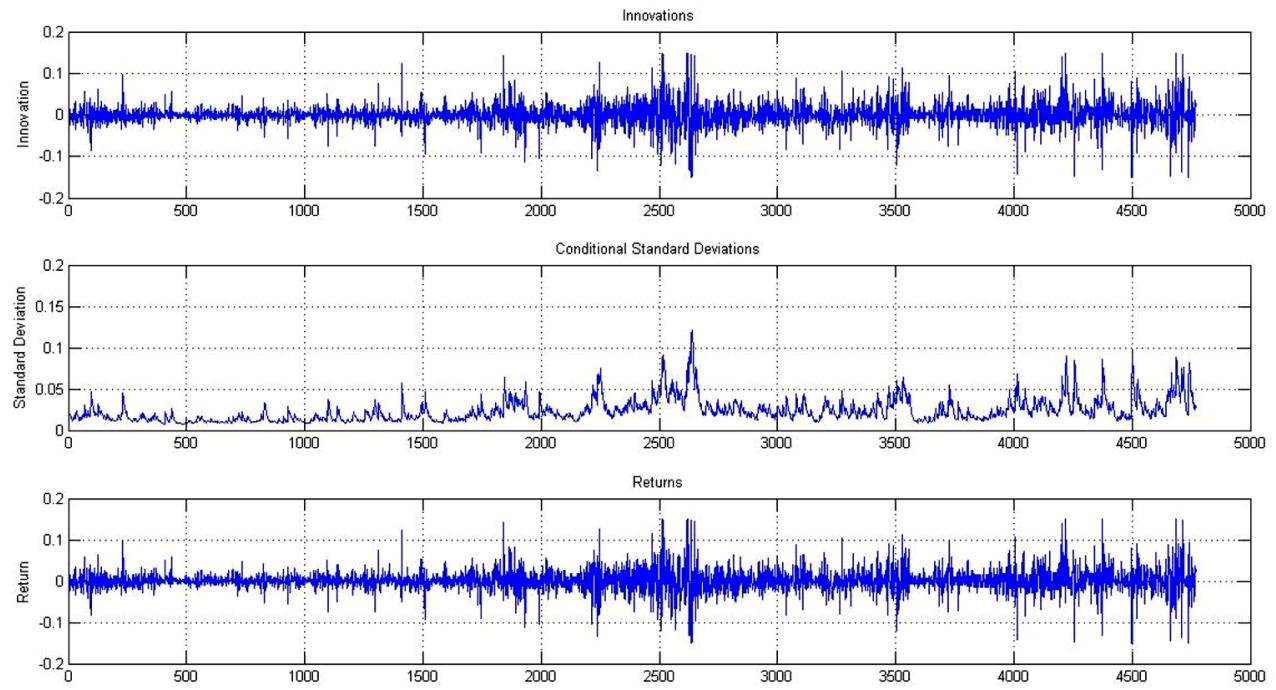

Figure 13. Innovations, Conditional standard deviation and Return charts (source: own processing based on the close prices SIF1 between $1 / 1 / 2000 \div 5 / 13 / 2019$, on BSE. Results obtained in Matlab) 


\section{Results}

The future market seems to be the best place to bet on the forward title's prices. Unfortunately, the presence of arbitrage (hedging) opportunities cancels the possibilities of investors (speculators) opinions to be listed on the market. The best example of protection against arbitration is betting (Fong, 2014). We mention that the martingale strategy is not part of the arbitrage category. The No Arbitrage principle, recognized in the: "There is no such a thing as a free lunch" phrase, is a fundamental economic principle in any free market. It states that you cannot gain more through arbitrage than it would be by buying secure bonds on said market. The explanation is simple: if there is such an opportunity, anyone will want to take advantage of it, so that the forces that govern the market will quickly close the gap. On foreign exchange markets, there are automated trading systems that track early occurring arbitrages and exploit them. They occur when the same security is traded on different markets, or when there are differences between the spot and futures quotations, when markets do not react quickly enough at sudden price variations. Systems must be automated because the emergence of arbitrage opportunities is hard to observe and is rapidly absorbed by the market.

Due to arbitrage (Thomsett, 2017), the forward price of non-dividend shares must be equal to the current price update using the risk-free rate:

$$
F_{0}=S_{0} e^{r T},
$$

where $F_{0}$ forward contract price at $T=0$ date, $S_{0}$ the underline asset that provides no income price, $r$ the risk-free rate and $T$ time to maturity. This observation destroys the possibility for investors to display the quotation they expect over a period, the forward price being irrelevant to the prediction of the stock market evolution. Thus, the forward price of the shares results from the quotation of the bonds, which is paradoxical, the two being unrelated (Figure 14). It should be noted that the spot price (which should be forecasted to

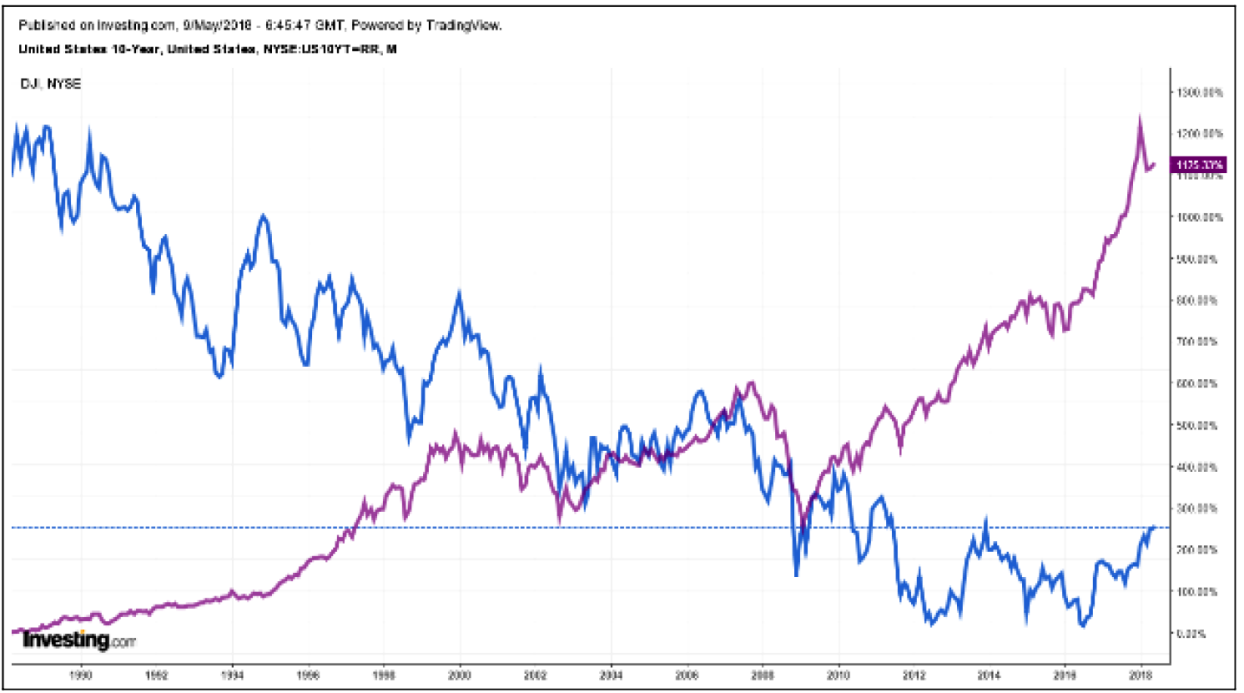

Figure 14. Comparison between DJIA and 10-year US bond (source: own processing created on the website investing.com, 2019) 
conclude forward contracts) has nothing to do with the evolution of interest rates on bonds (considered without risk). In fact, in theory, they should evolve in the opposite direction, being inversely correlated. It is therefore unreasonable to list a forward contract based on a formula that uses a parameter ( $r$ ) that has nothing to do with the expected evolution of the object of the contract.

The futures price is affected even more by arbitrage: basically, it cannot differ from the spot price, because of immediately emerging risk-free opportunities. The paradox reveals immediately. Suppose at the beginning of the period, when the price is 1 unit, we forecast that by the end of the period the price will be 2 units. However, we cannot quote neither forward nor futures at 2 units, because the arbitrators will sell one contract at price level 2, and will simultaneously buy the equivalent number of stocks on spot (based on the leverage of the derivative), so that at maturity (when the two prices will mathematically equal) will earn 1 unit risk-free. Consequently, futures prices may differ only slightly from spot prices, both in terms of time and value Thus, future quotations no longer represent the participants' opinion on the price at maturity, but only their opinion if the rate will rise or fall.

Although there have been many counterexamples on the Romanian market during the boom market, the situation is not natural, generating a new paradox (Table 1). There were consistent arbitrage opportunities, with consistent returns (much above bank or government bond yields) and without any risk (practical, free money). The explanation for which few investors have turned to arbitrage, or hedging is that stock market has had a fulminating evolution, with annual returns steadily superior to those offered by arbitrage, speculators forgetting the inherent risks of an exponential growth.

Table 1. Arbitrage opportunities on Romanian market (source: own processing)

\begin{tabular}{|c|c|c|c|c|c|c|c|c|}
\hline Title & spot BVB & $\begin{array}{c}\text { Delivery } \\
\text { date }\end{array}$ & $\begin{array}{c}\text { Future } \\
\text { BMFMS }\end{array}$ & Difference & $\begin{array}{l}\text { Invest- } \\
\text { ment }^{*}\end{array}$ & Profit & $\begin{array}{l}\text { Time } \\
\text { (month) }\end{array}$ & $\begin{array}{c}\text { Annua- } \\
\text { lized profit }\end{array}$ \\
\hline \multirow{3}{*}{ SIF2 } & \multirow{3}{*}{1.52} & sep-08 & 1.588 & 0.07 & \multirow{3}{*}{2.220} & $3.06 \%$ & 1.2 & $30.63 \%$ \\
\hline & & dec-08 & 1.680 & 0.16 & & $7.21 \%$ & 4.2 & $20.59 \%$ \\
\hline & & mar-09 & 1.750 & 0.23 & & $10.37 \%$ & 7.2 & $17.29 \%$ \\
\hline \multirow{3}{*}{ SIF5 } & \multirow{3}{*}{1.65} & sep-08 & 1.686 & 0.04 & \multirow{3}{*}{2.550} & $1.41 \%$ & 1.2 & $14.12 \%$ \\
\hline & & dec-08 & 1.760 & 0.11 & & $4.31 \%$ & 4.2 & $12.32 \%$ \\
\hline & & mar-09 & 1.900 & 0.25 & & $9.80 \%$ & 7.2 & $16.34 \%$ \\
\hline
\end{tabular}

${ }^{*}$ Investment $=1000 \times(\mathrm{BVB})+2 \times($ BMFMS margin $)$

BMFMS Futures market 2008-08-23 07:51:03

The definition of the futures contract is: "A futures contract is an agreement to buy or sell an asset at a certain time in the future for a certain price" (Hull, 2018). However, participants bet only on the direction of the variance (the buyer on the increase, the seller on the decrease) and in no case on the value of the price at the due date, as required by the definition. As for option theory (Black-Scholes-Merton), Fischer Black himself recognized that the theory had at least nine flaws and incorrect assumptions (Thomsett, 2017). Neither exotic options nor certificates provide methods to predict the evolution of quotations, but at 
most its direction estimation (by adopting a sell or buy position). Although some regulators do not really agree with binary options, they are a good example of a stock market forecast, albeit in the short term. Binary options are most likely to predict the evolution of the stock exchange prices until the end of the day (or later, but usually very close in time). Many sites offer the public the opportunity to use these options.

Why would a site that offers betting on future stock prices be interesting? First, because quotations would be set by professionals with experience in calculating probabilities. Then, because it would allow no mistakes, the assessment of the evolution should be as accurate as possible. Although not complete, arbitrage would be ruled out, so everyone could concentrate on prices on a futures date. It should be noted that this distribution will not be based on the Gauss model (which is not applicable to the capital market nor to sports betting - where Poisson (Karlis \& Ntzoufras, 2003) distribution is preferred), not only statistics is to take into account, methods for valuing options are not useful, corporate financial data (once they occur), the general feelings of the market and any unexpected event occurrence must be considered.

Quotations should follow the probability theory to avoid the Dutch book construction (Jeffrey, 2004), i.e. the sum of probabilities must be 100\% (or slightly higher if we consider the profit of the brokerage house). Therefore, this problem is completely open, the actual introduction of such bets contributing to the development of both prediction practice and theoretical ones. Although there must be a degree of control (because market manipulation may occur to influence the price of betting) (Anderson, Blackshaw, Siekmann, \& Janwillem, 2012), avoiding supervision by market institutions can leave room for imagination, contributing to the free pricing of quotes (they should not be justified, as is the case with forecasts provided by brokers/consultants).

The most likely price will be:

$$
c=\sum c_{i} \times p_{j}
$$

with $p_{i}$ being the probability of price $c_{i}$.

Because it's a bet initiated by bookmakers and bitcoin is not officially recognized as a currency, this is the best example of forecasting the evolution of the financial markets, with odds being set solely based on the specialists' forecasts. Complying with probability laws would be particularly important. For example, the sum of probabilities (quotation inversion) must be $100 \%$ (possibly slightly higher, considering the long-term winnings of the bookmaker). This rule is also to be respected among bookmakers (Figure 15), otherwise gamblers can find safe wining possibilities. After settling their odds, the bookmakers reconcile their odds among each other, so that arbitrage gain is impossible (meaning betting on the same match, the client earns no matter what the result will be).

This is the main disadvantage of the betting approach: a bookmaker cannot show odds which might be much different from the others, even if it possesses special information or a better estimation method, because it gives gamblers the chance to win regardless of the outcome (the equivalent of arbitration). According to Table 2, probabilities are the inverse of the odds proposed by bookmakers. For example, odds of 2.20 mean the probability of the betting event for the event being $1 / 1.20=45 .(45) \%$. In order to be a winner in the long run, the amount of betting probability exceeds $100 \%$ for any match. For example, 18bet quotes the following: $1 / 2.20+1 / 3.90+1 / 2.85=106.18 \%(=1 / 94.2 \%$ pay-out $)$. However, if the 


\section{Real Madrid - Liverpool}

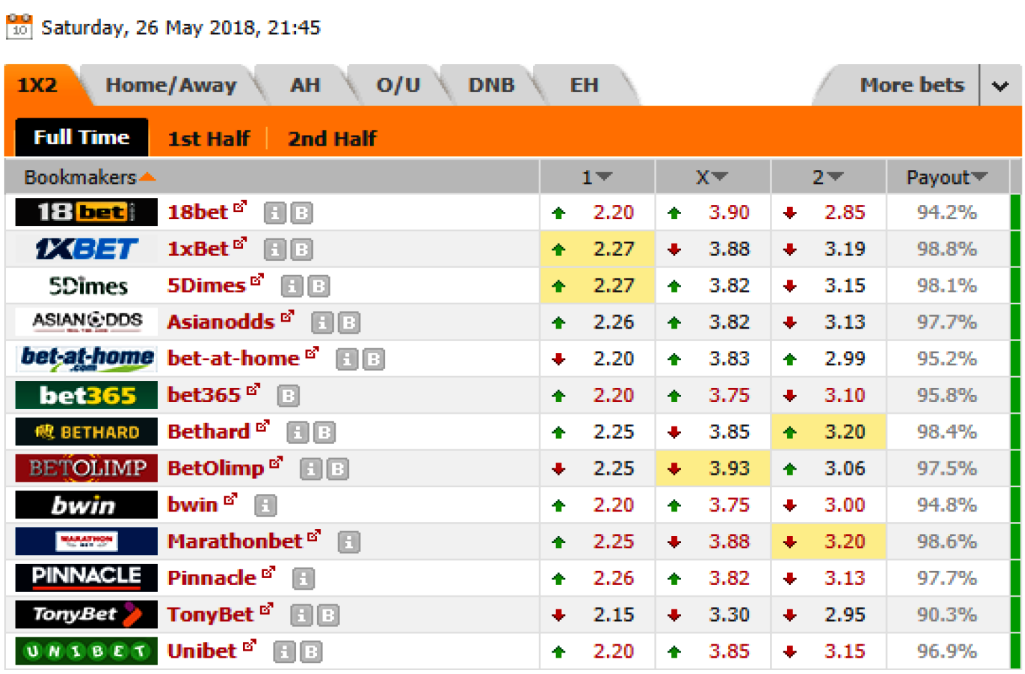

Figure 15. Comparison between bookmaker odds (source: data available on Oddsportal.com, 2017-2018)

bookmakers would independently rank the results, the opportunity could be that all odds $(1 \times 2)$ would exceed 3 , so regardless of the outcome, the customer would win by betting the same amount on all the results and collecting more than the amount played regardless of the outcome. Also, the sum of probabilities must exceed $100 \%$, even if the quotes are combined from several bookmakers. A hypothetical example constructed so that this condition is not met, which results in a certain customer's gain, is presented in Table 2.

Table 2. Unreconciled quotes (source: own processing)

\begin{tabular}{|c|c|c|c|c|}
\hline \multirow{2}{*}{ Bookmaker } & \multicolumn{3}{|c|}{ Quotes } & \multirow{2}{*}{$\begin{array}{c}\text { Total } \\
\text { probabilities }\end{array}$} \\
\cline { 2 - 4 } & 1 & $X$ & 2 & 1.0500 \\
\hline $\mathrm{A}$ & 2.5 & 2.5 & 4.0 & 1.0476 \\
\hline $\mathrm{B}$ & 2.8 & 2.8 & 3.0 & 0.9643 \\
\hline $1 B+X B+2 A$ & 2.8 & 2.8 & 4.0 & \\
\hline
\end{tabular}

Although the odds seem not to differ substantially, the client can play a variation where the total probability is below $100 \%$ : bet 1 at house $B, X$ at $B$ and 2 at house $A$. The situation will be redeemed by the customer, who will bet $\$ 10$ on 1 to $B, \$ 10$ on $X$ to $B$ and $\$ 7$ on 2 to $A$. Thus, he has a total bet of $\$ 27(=10+10+7)$ and will win $\$ 28$ regardless of the result: $10 \times 2.8$ if 1 on house $B, 10 \times 2.8$ for $X$ on $B$ and $7 \times 4=\$ 28$ on $A$ in case of result 2 (Table 2 ).

Obviously, the probability calculation must be very accurate, otherwise mathematical quoting errors may occur. An example is given in Figure 16. It is noted that the same score, $0-0$, is quoted differently if it refers to the exact result, the total number of goals, respectively the time of scoring. 


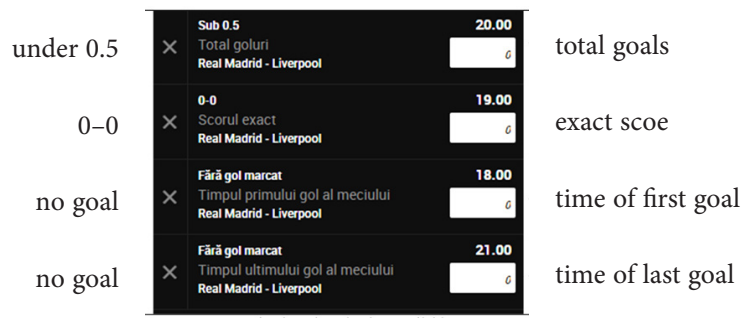

Figure 16. Wrong quotations

(source: own processing based on the data available on UNIBET, 2019)

\section{Discussion and recommendations}

This paper insists on the theoretical and practical shortcomings of the main approaches to the capital market, as the benefits have been presented in the current state of knowledge. It was not found a universally applicable theory, and if it exists, it would create a paradox in that by applying it, most of the brokers would no longer have counterpart for doing the transactions. As a matter of fact, practitioners in the market do not all have the same vision, which makes the stock market delight, each fighting for one's own idea over others. On the capital market, the main paradox is that everyone would reasonably want to be able to accurately predict the evolution of their securities. This would lead to a lack of interest in the trading of that issuer. Subsequently, paradoxes concern various theories, which either start from unconfirmed premises, or are poorly theoretically founded (academic) but bring good results on the market.

If the paradox that it is base the investment on a future that is uncertain would have been avoided (for example, through a theory that provides very well market developments) another paradox would intervene: knowing the future, no one would trade anymore. If there is a security that will bring a good return, the owner will not sell it if the security will have a sub-performer, nobody will buy it. Perhaps gold, as a defensive asset, makes an exception: it is traded and stored (creating reserves) not only to gain from the price increase. The second paradox is even more un pleasant: there is no universal benchmark against which to relate prices. Any valuation is a price comparison, regardless of the approach selected: the cost of construction / replacement of similar assets in the cost approach, the asset type market for the comparative approach, the discount rate and the issuer's history to forecast the value through income. Therefore, the valuation of art work is often flagrantly invalided in auctions: comparable only offer vague elements that the appraiser can rely upon.

International and European Valuation Standards present the best practice without detailed calculations or needed parameters to establish the actual value. It is not taken into consideration investors' psychology, and it doesn't explain the criteria of price formation (utility, rarity, desire, possibility) and only represent a professional opinion

All approaches in valuation, although not recognized by standards, have common points:

- Are based on comparison with other similar assets. The cost approach determines the reconstruction / replacement price by comparing with other identical / similar assets, the income approach is based on market capitalization rates and past experiences (by comparison) and the market approach is defined as a comparative method. 
- It refers to the future, without even trying to predict it. Capitalization rate is the current one but applies to future earnings. The most widely used stock multiplier is PER estimated over 2 years, the PEG also earns ground (also based on linear extrapolation). The cost approach is anchored in the past, which is why it is less commonly used: investors question the use of their assets for future business.

- By applying market multipliers, the methods are uniformized. At listed companies, the audited financial statements should reflect the fair value of the assets. By applying a $\mathrm{P} / \mathrm{BV}$ close to 1 , a link is bridged between the patrimonial and the market approach. PER, although calculated for the already realized profit (not foreseen, as used by brokers, links the market value of the shares to the yield value (it is the inverse of the capitalization rate but the profit-specific rather than the cash-flow).

This results of this article recommends to all theoreticians and practitioners caution in the practical application of theories on the stock market, because the phrase known by all the investors: the market is always right, actually meaning that no matter how good the theory is, the practice kills us. As a result of the study, it would be necessary to develop new theories or new intervention of the practical results, the current approaches proving insufficient to guarantee a constant good result on the stock exchange.

\section{Conclusions}

The main conclusion is that it can't be identified a valid theory to properly model the capital market. Correct mathematical theories are not compliant in practice. The result is natural if it refers about how mathematical logic works: the implication is true unless the hypothesis is false and the conclusion true. That is, if the assumptions are not consistent with market realities, any conclusion that it is draw by applying correct mathematical formulas may be inapplicable. So the problem does not consist of selecting applied mathematics or in the correctness of calculations, but in modelling the phenomenon itself. The conclusions of this article reveal that probability methods are not considered to be the most suitable for scientific study and practical problem solving. It is not referring here to the numerous errors in the application of statistics, or to the inherent paradoxes, nor to the subjectivity induced by Bayes' theorem. The article states that statistical/ probabilistic approaches are only applicable where there is no conditionality imposed by objective laws.

The stock exchange market is made up of people: they are the ones who trade or set the parameters of machines that automate the process. Their behaviour is unpredictable, subjective. It is not possible to establish an objective law on the evolution of securities. Thus, it remains as unique explanation the appliance of probability theories in what regard their actions. But which statistics should be applied? There is also a flock spirit. It determines the trends of the technical analysis and overpresses the issuer's data. The results should not be surprised: the phenomenon also occurs in physics (Metronome). Start the metronomes random and wait a few minutes; they will synchronize perfectly.

Trying to beat the market equates to wanting to score more goals on your own than your own team. Long term surpassing the buy \& hold strategy is something normal, any technical analyst can succeed. To compare yourself to the market means to use stock indicators as a benchmark (target). Valuations (DCFs) are made as a market capitalization rate. However, 
any investor may use a rate that meets his / her expectations, provided they are realistic. Portfolio selection remains an open problem. But as long as the valuation does not tell us anything about the predicted evolution of quotations, when academic theories do not yield better than the average $1 / \mathrm{n}$, and technical and fundamental analysis are not in a coherent logic of investment recommendations, the choice of securities in a portfolio remains an art.

The results obtained in this article suggest that there are good mathematical theories, but based on imprecise predictions, respectively good empirical results that defy exact theories. There cannot be identified adequate predictions of market developments or infallible procedures to react quickly to changes in its direction.

The best approach to predict market evolution is represented by bookmaker's type quotations, because it would avoid the issue of arbitrage, but also over-regulation on stock exchanges. The study concludes that if there is a good long-term outcome forecast for betting quotas that would be the key to the long-lasting success of a persistent investor.

Other directions of study should be mentioned:

- Machine learning, especially in the exponential development of automatic trading software;

- Adaptive techniques: technical analysis;

- Behavioral finance;

- Intelligent system techniques: genetic algorithms, rule-based expert systems, neural networks, support vector machines;

The path of future research can be focused in the following directions:

- Practical methods for determining the subjective probabilities for the evolution of titles;

- Establishing the mathematical relationship between the probabilities of daily variations and the probability of quotation over a given time frame;

- Practical establishment of the correlation between titles, including the similarity of predictions on future values;

- Selection of portfolio titles based on probabilities attached to future quotations;

- Assessment approaches based on subjective probabilities; replacing the empirical risk included in cost of capital with the risk determined by the distribution of calculated probabilities.

\section{Acknowledgements}

The authors thank the anonymous reviewers and editor for their valuable contribution.

\section{Funding}

This research received no specific grant from any funding agency in the public, commercial, or not - for - profit sectors.

\section{Author contributions}

FT and FCD conceived the study and were responsible for the design and development of the data analysis. PB were responsible for data collection and analysis and also for data interpretation. $\mathrm{MB}$ was responsible for the literature review section. 


\section{Disclosure statement}

The authors have not any competing financial, professional, or personal interests from other parties.

\section{References}

Aladesanmi, O., Metcalf, H., \& Casalin, F. (2018). Stock market integration between UK and US: An empirical analysis on 8-decade long - data, Global Finance Journal, 41(C), 32-43.

https://doi.org/10.1016/j.gf.2018.11.005

Alțăr, M. (2002). Teoria portofoliului. București: Academia de Studii Economice.

Anderson, P., Blackshaw, I., Siekmann, R., \& Janwillem S. (2012). Sports betting: Law and policy. Berlin Heidelberg: Springer-Verlag Asser Press. https://doi.org/10.1007/978-90-6704-799-9

ANEVAR. (2018). Standardele de evaluare a bunurilor.

Anghel, A., Dumitrescu, D., \& Tudor, C. (2015). Modeling portfolio returns on Bucharest Stock Exchange using the Fama-Frech multifactor model. Romanian Journal of Economic Forecasting, XVIII(1), 22-46. Retrieved from http://www.ipe.ro/rjef/rjef1_15/rjef1_2015p22-46.pdf

Anghel, D. G. (2017). Intraday market efficiency for a typical Central and Eastern European stock market. Romanian Journal of Economic Forecasting, XX(3), 88-109. Retrieved from http://www.ipe. ro/rjef/rjef3_17/rjef3_2017p88-109.pdf

Arneric, J., \& Scrabic-Peric, B. (2018). Panel Garch model with cross-sectional dependence between CEE emerging markets in trading day effects analysis. Romanian Journal of Economic Forecasting, XXI(4), 71-84. Retrieved from http://www.ipe.ro/rjef/rjef4_18/rjef4_2018p71-84.pdf

Azevedo, J. M., Almeida, R. M. P., \& Almeida, D. P. (2012). Using data mining with time series in short - term stock prediction: A literature review. International Journal of Intelligence Sciences, 2(4A), 176-180. https://doi.org/10.4236/ijis.2012.224023

Baker, H. K., \& Filbeck, G. (2013). Portfolio theory and management. Oxford University Press. https://doi.org/10.1093/acprof:oso/9780199829699.001.0001

Bako, E. D., \& Sechel, I. C. (2013). Technical and fundamental anomalies. Paradoxes of stock exchange markets. Annals of Faculty of Economic, University of Oradea, 1(1), 37-43. Retrieved from https:// ideas.repec.org/a/ora/journl/v1y2013ilp37-43.html

Brynjolfsson, E., Rock, D., \& Syverson, C. (2017). Artificial intelligence and the modern productivity paradox: A clash of expectations and statistics. NBER Working Paper No. 24.001, 1-44. Retrieved from http://faculty.chicagobooth.edu/chad.syverson/research/aiparadox.pdf

Betfair. (2019). Retrieved from https://www.betfair.ro/exchange/plus/financial-bets

Bucharest Stock Exchange. (2019). Retrieved from https://www.bvb.ro/FinancialInstruments/Details/ FinancialInstrumentsDetails.aspx? $\mathrm{s}=\mathrm{SIF} 1$

Cartwright, E. (2018). Behavioral economics. London: Routledge. https://doi.org/10.4324/9781315105079

Chen, J. (2010). Essentials of technical analysis for financial markets. John Wiley \& Sons, Inc.

Damian, V., \& Cepoi, C. O. (2016). Volatility estimators with high-frequency data from Bucharest Stock Exchange. Economic Computation and Cybernetics Studies and Research, 50(3), 247-264. Retrieved from http://www.ecocyb.ase.ro/nr20163/14\%20-\%20DAMIAN\%20Virgil,\%20Cosmin\%20 $\% 20$ Cepoi\%20(T).pdf

Degutis, A., \& Novickyte, L. (2014). The efficient market hypothesis: A critical review of literature and methodology. Economika, 93(2), 7- 23. https://doi.org/10.15388/Ekon.2014.2.3549 
Demirer, R., Pierdzioch, C., \& Zhang, H. (2017). On short - term predictability on stock returns: A quantile boosting approach. Finance Research Letters, 22, 35-41. https://doi.org/10.1016/j.frl.2016.12.032

De Prado, M. L. (2018). Advances in financial machine learning. New York: John Wiley \& Sons, Inc.

Elton, E., Gruber, M., Brown, S., \& Goetzmann, W. (2014). Modern portfolio theory and investment analysis (9th ed.). New York: John Wiley \& Sons, Inc.

Fahling, E., Steurer, E., Schadler, T., \& Voltz, A. (2018). Next level in risk management? Hedging and trading strategies of volatility derivatives using VIX futures. Journal of Financial Risk Management, 7, 442-459. https://doi.org/10.4236/jfrm.2018.74024

Francis, J. C., \& Kim, D. (2013). Modern portfolio theory. Foundations, analysis, and new developments. John Wiley \& Sons, Inc., Hoboken, New Jersey.

Franco, C., \& Zakoian, J. M. (2010). GARCH models: structure, statistical inference, and financial applications. New York: John Wiley \& Sons Ltd. https://doi.org/10.1002/9780470670057

Fong, W. M. (2014). The lottery mindset: Investors, gambling and the stock market. New York: Palgrave Macmillan. https://doi.org/10.1057/9781137381736

Fulga, C. (2017). Integrated decision support system for portfolio selection with enhanced behavioral content. Economic Computation and Cybernetics Studies and Research, 51(3), 127-142. Retrieved from http://www.ecocyb.ase.ro/nr2017_3/08\%20-\%20Fulga\%20Cristinca\%20(T)(N).pdf

Gao, L., Han, Y., Zhengzi Li, S., \& Zhou, G. (2018). Market intraday momentum. Journal of Financial Economics, 129(2), 394-414. https://doi.org/10.1016/j.jfineco.2018.05.009

Georgescu, V. (2016). Using nature-inspired metaheuristics to train predictive machines. Economic Computation and Cybernetics Studies and Research, 50(2), 5-24. Retrieved from http://www.ecocyb. ase.ro/nr20162/01\%20-\%20Georgescu\%20Vasile\%20(T).pdf

Hull, J. (2018). Options, futures, and other derivatives (10th ed.). New York: Pearson Education.

ifbf Finwest. (2019). Retrieved from https://www.ifbfinwest.ro

investing.com. (2019). Retrieved from https://www.investing.com

International Valuation Standards Council. (2017). International Valuation Standards.

Jeffrey, R. (2004). Subjective probability. The real thing. Cambridge: Cambridge University Press. https://doi.org/10.1017/CBO9780511816161

Javadi, F., Ftiti, Z., \& Hdia, M. (2017). Assessing efficiency and investment opportunities in commodities: A time series and portfolio simulations approach. Economic Modeling, 64, 567-588. https://doi.org/10.1016/j.econmod.2017.04.021

Joldes, C. C. (2019). Modeling the volatility of the Bucharest Stock Exchange using the GARCH models. Economic Computation and Cybernetics Studies and Research, 53(1), 281-298. Retrieved from http:// www.ecocyb.ase.ro/nr2019_1/18\%20-\%20Joldes\%20Camelia\%20Catalina\%20(18).pdf

Jerald, E. P., Robinson, T. R., Pinto J. E., \& McLeavey, D. W. (2010). Equity asset valuation (2nd ed.). New Jersey: CFA Institute.

Karlis, D., \& Ntzoufras, I. (2003). Analysis of sports data by using bivariate Poisson models. The Statistician, 53(3), 381-393. https://doi.org/10.1111/1467-9884.00366

Lim, M. A. (2016). The handbook of technical analysis. Singapore: John Wiley \& Sons Singapore Pte. Ltd.

Litov, L., Moreton, P., \& Zenger, T. R. (2012). Corporate strategy, analist coverage and the uniqueness paradox. Management Sciences, 58(10), 1797-1815. https://doi.org/10.1287/mnsc.1120.1530

Longarela, I. R., \& Mayoral, S. (2015). Quote inefficiency in options markets. Journal of Banking and Finance, 55(C), 23-36. https://doi.org/10.1016/j.jbankfin.2014.11.003

Lungu, I., Bâra, A., Cărutaşu, G., Pîrjan, A., \& Oprea, S. V. (2016). Prediction intelligent system in the field of renewable energies through neural networks. Economic Computation and Cybernetics 
Studies and Research, 50(1), 85-102. Retrieved from http://www.ecocyb.ase.ro/nr20161/05\%20-\%20 Lungu\%20Ion,\%20final\%20(T).pdf

Lupu, I. (2015). European stock markets correlations in a Markov switching framework. Romanian Journal of Economic Forecasting, XVIII(3), 103-119. Retrieved from http://www.ipe.ro/rjef/rjef3_15/ rjef3_2015p103-119.pdf

Lupu, I., Hurduzu, G., \& Nicolae, M. (2016). Connections between sentiment indices and reduced volatilities of sustainability stock market indices. Economic Computation and Cybernetics Studies and Research, 50(1), 157-174. Retrieved from http://www.ecocyb.ase.ro/nr20161/09\%20-\%20Lupu\%20 Hurduzeu\%20Nicolae\%20(T).pdf

Mago, T., Wang, X., \& Modave, F. (2010). Application of fuzzy measures and interval computation to financial portfolio selection. International Journal of Intelligent Systems, 25, 621-635. Wiley Periodicals, Inc. https://doi.org/10.1002/int.20415

Markowitz, H. M. (1952). Portfolio selection. The Journal of Finance, 7(1), 77-91. https://doi.org/10.2307/2975974

Marcu, N., Dobrotă, C. E., \& Antoneac (Calin), R. (2017). An investigation of the day-of-the-week effect in conditional variance at the Bucharest Stock Exchange. Romanian Journal of Economic Forecasting, $X X(2), 124-134$. Retrieved from http://www.ipe.ro/rjef/rjef2_17/rjef2_2017p124-134.pdf

Murphy, J. (1999). Technical analysis of the financial markets. New York: New York Institute of Finance.

Oddsportal.com. (2017-2018). Retrieved from http://www.oddsportal.com/soccer/europe/championsleague/real-madrid-liverpool-hMiM2xC0/

Pati, P. C., Barai, P., \& Rajib, P. (2018). Forecasting stock market volatility and information content on implied volatility index. Applied Economics, 50(23), 2552-2568. https://doi.org/10.1080/00036846.2017.1403557

Pesavento, L., \& Smoleny, S. (2015). A trader's guide to financial astrology. Forecasting market cycles using planetary and lunar movements. New Jersey: John Wiley \& Sons, Inc., Hoboken. https://doi. org/10.1002/9781118646953

Pratt, S., \& Grabowski, R. (2010). Cost of capital: application and examples (4th ed.). New York: John Wiley \& Sons, Inc.

Pyun, S. (2019). Variance risk in aggregate stock returns and time-varying return predictability. Journal of Financial Economics, 132(1), 150-174. https://doi.org/10.1016/j.jfineco.2018.10.002

Richard, J. F. (2005). Bourse: Ce qu'anticipent les astre jusqu'en 2010. Astrologie. Paris: Éditions du rocher.

Ruxanda, G., \& Opincaru, S. (2018). Bayesian neural networks with dependent Dirichlet process priors. Application to pairs trading, Economic Computation and Cybernetics Studies and Research, 52(4), 5-18. Retrieved from http://www.ecocyb.ase.ro/nr2018_4/01\%20-\%20Ruxanda\%20Gh.,\%20 Sorin\%20Opincariu.pdf

Sappideen, R. (2009). The paradox of securities markets efficiency: Where to next? Singapore Journal of Legal Studies, Special Issue, 1(1), 80-108. Retrieved from https://papers.ssrn.com/sol3/papers. cfm?abstract_id=1491370

Saman, C. (2015). Asymmetric interaction between stock price index and exchange rates: Empirical evidence for Romania. Romanian Journal of Economic Forecasting, XVIII(4), 90-109. Retrieved from http://www.ipe.ro/rjef/rjef4_15/rjef4_2015p90-109.pdf

Schmidlin, N. (2014). The art of company valuation and financial statement analysis. New York: Verlag Franz Vahlen GmbH (John Wiley \& Sons Ltd.).

Schulmerich, M., Leporcher, Y. M., \& Eu, C. H. (2015). Applied asset and risk management. A guide to modern portfolio management and behavior-driven markets. Berlin Heidelberg: Springer-Verlag.

Sharpe, W. F. (1964). Capital asset prices: A theory of market equilibrium under conditions of risk ${ }^{\star}$. The Journal of Finance, XIX(3), 425-442. https://doi.org/10.1111/j.1540-6261.1964.tb02865.x 
Shim, H., Kim, H., Kim, J., \& Ryu, D. (2015). Weather and stock market volatility: the case of a leading emerging market. Applied Economics Letters, 22(12), 987-992. https://doi.org/10.1080/13504851.2014.993129

Singht, V., Roca, E., \& Li, B. (2018). Cointegration networks in stock markets. Applied Economics Letters, 25(10), 663-667. https://doi.org/10.1080/13504851.2017.1355534

Smales, L. A. (2017). The importance of fear: investor sentiment and stock market returns. Applied Economics, 49(34), 3395-3421. https://doi.org/10.1080/00036846.2016.1259754

Stadnik, B., Raudeliuniene, J., \& Davidaviciene, V. (2016). Fourier analyzing for stock price forecasting: Assumption and evidence. Journal of Business Economics \& Management, 17(3), 365-380. https://doi.org/10.3846/16111699.2016.1184180

Stooq. (2019). Retrieved from https://stooq.com/q/d/?s=^dji

Symitsi, E., Symeonidis, L., Kourtis, A., \& Markellos, R. (2018). Covariance forecasting in equity markets. Journal of Banking \& Finance, 96, 153-168. https://doi.org/10.1016/j.jbankfin.2018.08.013

Sortino, A., \& Price, L. (1994). Performance measurement in a downside risk framework. The Journal of Investing, III(3), 59-64. https://doi.org/10.3905/joi.3.3.59

Sortino, F. A., \& Satchell, S. E. (2001). Managing downside risk in financial markets: Theory, practice and implementation. Reed Educational and Professional Publishing Ltd.

Taleb, N. N. (2017). The black swan: The impact of the highly improbable. New York: Random House.

Tsinaslanidis, P. E., \& Zapranis, A. D. (2016). Technical analysis for algorithmic pattern recognition. Bern: Springer International Publishing Switzerland. https://doi.org/10.1007/978-3-319-23636-0

Thomsett, M. (2017). The mathematics of options. New York: Palgrave Macmillan. https://doi.org/10.1007/978-3-319-56635-1

Turcaș, F., Dumiter, F., Braica, A., Brezeanu, P., \& Opreț, A. (2016). Using technical analysis for portfolio selection and post-investment analysis. Economic Computation and Cybernetics Studies and Research, 50(1), 197-214. Retrieved from http://www.ecocyb.ase.ro/nr20161/12\%20-\%20Turcas\%20 Florin,\%20Demeter\%20(T).pdf

Turcaș, F., Dumiter, F., Brezeanu, P., Fărcaș, P., \& Coroiu, S. (2017). Practical aspects of portfolio selection and optimization on capital market. Economic Research-Ekonomska Istraživanja, 30(1), 14-30. https://doi.org/10.1080/1331677X.2016.1265893

Turcaş, F., Dumiter, F., Braica, A., Brezeanu, P., \& Neagu, O. (2018). Arbitrage on Romanian stock market. Economic Computation and Cybernetics Studies and Research, 52(1), 43-58. Retrieved from http://www.ecocyb.ase.ro/nr2018_1/03\%20-\%20Turcas\%20Florin,\%20P.\%20\%20Brezeanu\%20(T). pdf

Turcaş, F. (2008). Strategia X și 0, AATROM.

UNIBET. (2019). Retrieved from https://www.unibet.ro

Zhang, H. (2018). The forecasting model of stock price based on PCA and BP neural network. Journal of Financial Risk Management, 7, 369-385. https://doi.org/10.4236/jfrm.2018.74021

Zhang, Y., Zeng, Q., MA., F., \& Shi, B. (2019). Forecasting stock returns: Do less powerful predictors help? Economic Modeling, 78, 32-39. https://doi.org/10.1016/j.econmod.2018.09.014

Zivkov, D., Njegic, J., \& Milenkovic, I. (2018). Interrelationship between DAX Index and Four Largest Eastern European Stock Markets. Journal for Economic Forecasting, Institute for Economic Forecasting, $0(3), 88-103$. 